\title{
Solitary living in Alzheimer's disease over 3 years: association between cognitive and functional impairment and community-based services
}

This article was published in the following Dove Press journal:

Clinical Interventions in Aging

14 November 2014

Number of times this article has been viewed

\section{Carina Wattmo \\ Elisabet Londos \\ Lennart Minthon}

Clinical Memory Research Unit, Department of Clinical Sciences, Malmö, Lund University, Malmö, Sweden
Correspondence: Carina Wattmo Memory Clinic, Skåne University Hospital, SE-205 02 Malmö, Sweden Tel +46 4033560 I

Fax +46 40335657

Email carina.wattmo@skane.se
Introduction: Many individuals with Alzheimer's disease (AD) live alone, and this figure is expected to increase. This study aimed to describe the cognitive and functional abilities of solitary-living AD patients, and the potential predictors of their usage of community-based services.

Methods: This 3-year, prospective, multicenter study included 1,021 participants with mildto-moderate AD (Mini-Mental State Examination score, 10-26) treated with a cholinesterase inhibitor in a routine clinical setting. At baseline and every 6 months, patients were assessed using cognitive, instrumental, and basic activities of daily living (ADL) scales, and service utilization was recorded. Logistic regression models were used to predict the usage of community-based services.

Results: At the start of cholinesterase inhibitor therapy (time of AD diagnosis), 355 individuals $(35 \%)$ were living alone. They were mainly female, older, had more impaired basic ADL capacity, and had a larger number of concomitant medications when compared with those living with family. Regarding the solitary-living patients, lower instrumental ADL (IADL) ability and more medications were independent predictors of usage of home-help services, whereas more impaired IADL at baseline and faster IADL deterioration were predictors of nursing home admission. For those living with family, older age, lower basic ADL, and a greater number of medications predicted home-help services, whereas a larger amount of home help predicted nursing home placement. In addition, female sex was a risk factor for both the utilization of home-help services and nursing home placement. Cognitive ability was not significantly associated with the usage of community-based services.

Conclusion: A large number of AD patients, predominantly females, live alone with severe cognitive and functional impairment. The amount of home-help services used did not reflect cognitive severity, suggesting that home help did not meet the needs related to cognitive deterioration. Increased knowledge of how community-based services can better accommodate the care needs of solitary-living individuals with AD is essential.

Keywords: cognition, activities of daily living, living status, home-help services, nursing home placement, longitudinal study

\section{Introduction}

A large percentage of individuals (28\%-34\%) with Alzheimer's disease (AD) live alone in their own homes, ${ }^{1,2}$ and it is reasonable to assume that the number of solitaryliving elderly individuals with dementia will increase in the future. The longer life expectancy of humans implies the rise of AD prevalence rates. ${ }^{3}$ In Sweden, the number (percentage) of people aged 60 years and older who live alone has increased from about 
$299,000(23 \%)$ in 1960 to $768,000(32 \%)$ in $2012 .{ }^{4}$ These factors imply an additional pressure on the increasing societal costs of dementia care.

$\mathrm{AD}$ is characterized by a progressive and irreversible decline in cognition and activities of daily living (ADL). Even in mild $\mathrm{AD}$, a pronounced impairment in the ability to carry out instrumental ADL (IADL) tasks, such as shopping, housekeeping, handling finances, and traveling by bus or car, has been observed. ${ }^{5}$ Thus, AD is a devastating disease, as affected individuals experience a gradual loss of independence, as well as difficulties in making well-informed decisions and evaluating potential risks. ${ }^{6}$

The community-based care of persons with dementia is anticipated to increase in the future. ${ }^{3}$ Social structural changes, such as long geographical distances between adult children and their aging parents and the full-time working status of most women, imply limited informal help from family members. ${ }^{7}$ About $50 \%$ of the informal help received by AD patients has been reported to consist of surveillance, avoidance of repetitive or dangerous activities, and management of behavioral symptoms. ${ }^{8}$ Lack of help in monitoring these expressions of $\mathrm{AD}$ may lead to safety issues for individuals who live alone. Moreover, difficulties in detecting increasing impairment in their cognitive and functional abilities could negatively affect the opportunities of solitary-living individuals of receiving necessary formal help and medical care. ${ }^{9}$ Living alone with dementia is also a strong risk factor for nursing home placement, in particular among male patients. A study performed by our group found that the risk of nursing home placement for solitary-living males with $\mathrm{AD}$ was four times greater than that recorded for those living with a spouse or another relative. ${ }^{2}$

Several studies have investigated persons with dementia living alone. ${ }^{10-14}$ Nevertheless, different dementia diagnoses may yield different outcomes and amounts of service utilization. ${ }^{15,16}$ Studies exclusively including AD patients are few, and none are recent or have lasted longer than 1 year. ${ }^{1,9,11}$ Compared with participants not living alone, these studies showed that solitary-living individuals with AD were mainly females and had a lower income. ${ }^{1,9}$ However, inconsistent results regarding age ${ }^{9,11}$ and cognitive status ${ }^{1,9}$ were obtained. Home-help services are often the first community-based services that are used as AD progresses. Lower ADL capacity was a predictor of the presence and use of a larger amount of home health care among elderly persons with various diseases, whereas conflicting results regarding cognitive ability have been observed. ${ }^{17} \mathrm{~A}$ recent AD study from our group showed that better IADL performance, living with a family member, and higher doses of cholinesterase inhibitors (ChEIs) postponed the usage of home-help services and predicted fewer hours of home help. ${ }^{18}$ Two older crosssectional studies reported differences in service-utilization patterns - for example, the more frequent use of homemaking and home-delivered meals among solitary-living $\mathrm{AD}$ patients than among those living with family. ${ }^{9,11} \mathrm{~A}$ long-term investigation of the extent of impairment in people with $\mathrm{AD}$ living alone in their own homes and analyses of whether the amount of home-help services received is related to both cognitive and functional deficits has not been published previously. This knowledge is essential for service providers and health authorities.

This 3-year study aimed: 1) to describe the long-term cognitive and functional abilities of solitary-living individuals with $\mathrm{AD} ; 2$ ) to compare these outcomes with those of patients living with a family member; and 3) to identify the potential predictors of usage of community-based home-help services and nursing home placement for these two livingstatus groups.

\section{Methods}

\section{Study and subjects}

The Swedish Alzheimer Treatment Study (SATS) is a 3-year, prospective, open, nonrandomized, multicenter study that was undertaken to investigate the long-term effectiveness of ChEI treatment (donepezil, rivastigmine, and galantamine) in routine clinical practice. The participants' progression of $\mathrm{AD}$ was assessed from different clinical and societal perspectives, such as cognition, ADL, and the usage of community-based services (eg, home-help services and nursing home placement). Results from the SATS have been reported in several previous publications. ${ }^{2,5,18,19}$ In total, 1,258 outpatients with AD were recruited from 14 memory clinics located in diverse geographical parts of Sweden. Among them, 1,021 individuals had mild-to-moderate AD (Mini-Mental State Examination [MMSE] score, ${ }^{20}$ 10-26) at the start of ChEI treatment (baseline) and were included in the present study.

Before inclusion, all SATS participants underwent a thorough clinical examination to rule out other causes of dementia. Patients aged 40 years and older who received a clinical diagnosis of dementia as defined by the Diagnostic and Statistical Manual of Mental Disorders, 4 th edition, ${ }^{21}$ and possible or probable AD according to the criteria of the National Institute of Neurological and Communicative Disorders and Stroke and the Alzheimer's Disease and Related Disorders Association (NINCDS-ADRDA) ${ }^{22}$ were 
considered for inclusion in the SATS. Moreover, the participants were required to live in their own home with or without home-help services at the time of AD diagnosis, to have a responsible caregiver (generally the spouse or an adult child), and to be assessable using the MMSE at the start of ChEI therapy. Concomitant medications were documented at baseline and were allowed during the study, with the exception of memantine. The dates of eventual nursing home placement and death were recorded, as well as the date of, and reason for, any withdrawal from the SATS.

All patients and/or caregivers gave their written informed consent to participate in the study, which was conducted according to the provisions of the Helsinki Declaration and was approved by the Ethics Committee of Lund University, Lund, Sweden.

The SATS participants were investigated in a wellstructured 3-year follow-up program that evaluated cognition, IADL, basic ADL abilities, and the presence of service utilization every 6 months. Trained dementia nurses assessed the ADL performance and recorded the amounts of services used per week (if any) in an interview with the caregiver. After inclusion and the baseline evaluations, the patients were prescribed ChEIs as a part of the ordinary Swedish health care system, in accordance with the approved product labeling. The SATS is an observational study and the choice of ChEI agent and dose was left entirely up to the physician's discretion and professional judgment.

\section{Outcome measures}

Cognitive ability was evaluated using the MMSE, with scores ranging from 0-30; a lower score indicates more impaired cognition. The Instrumental Activities of Daily Living (IADL) scale ${ }^{23}$ consists of eight items: telephone usage; shopping; food preparation; housekeeping; doing laundry; mode of transportation; responsibility for own medications; and handling finances. Severity was scored per item: from 1 (no impairment) to 3-5 (severe impairment), for a total range of 8-31 points. Some of the instrumental tasks may be sex-dependent among elderly persons. Therefore, a mathematical correction of the sum of the IADL scores was performed to prevent those tasks from affecting the results. The equation used the data from the rated items to estimate a total score within the range of the total IADL scale. ${ }^{2}$ The Physical Self-Maintenance Scale (PSMS) ${ }^{23}$ consists of six items: toileting; feeding; dressing; grooming; physical ambulation; and bathing. Each item was scored on a range of 1 (no impairment) to 5 (severe impairment), thus allowing a total range of 6-30 points.
Home-help services mean that a professional helper comes to the individual's own home to help with daily domestic duties, such as preparing meals, cleaning, washing up, doing the laundry, shopping for necessities, and accompanying the care recipient outside the home, as well as providing help with the administration of the prescribed medications, moreover, assist with personal hygiene, toilet visits, bathing, dressing, and eating. Neither more advanced medical care or therapy (which is performed by registered district nurses, physical therapists, or occupational therapists), nor transportation services, meals-on-wheels, or help with managing finances are included in these services. The amount of home-help services provided was recorded in terms of number of hours per week.

Nursing home placement was defined as the permanent admission to a licensed skilled nursing facility with 24-hour care (ie, rehabilitative or respite care were not included). If hospitalization occurred prior to nursing home entry, the date of hospital admission was used. The rates of cognitive and functional changes in the individuals who were admitted to nursing homes were calculated as the change in score from baseline to the last assessment before nursing home placement, divided by the number of months that elapsed between these assessments. For those who were not admitted, the rates of change were computed as the change in score from baseline to their last assessment, divided by the number of months. To facilitate comparisons of rates of change in MMSE, IADL, and PSMS scores, change in score was converted to positive values (which indicated improvement) and negative values (which indicated worsening).

\section{Statistical analyses}

The IBM Statistical Package for the Social Sciences (SPSS) software (version 22.0; IBM Corporation, Armonk, NY, USA) was used to perform the statistical analyses. The level of significance was defined as $P<0.05$, if not otherwise specified, and all tests were two-tailed. One-way analysis of variance was performed to compare the differences between the means obtained for three independent groups, and independent-sample $t$-tests were used to compare the differences between the means for two groups. The $\chi^{2}$ test was used for the analysis of categorical variables. Pearson's correlation coefficient was calculated to investigate any linear associations between continuous variables.

Binary logistic regression analyses using the backward likelihood ratio method were used to predict the presence of home-help services at the start of ChEI treatment and nursing home admission during the study for those living alone or with 
family, respectively. The Hosmer-Lemeshow goodness-of-fit test result was $>0.05$ for all four regression models, indicating a good fit of the model to the data. Regarding the home-help service models, the independent variables were classical risk factors, such as age at baseline, sex, and years of education; the genetic risk factor of the presence of the apolipoprotein $\mathrm{E}$ (APOE) $\varepsilon 4$ allele (no/yes); cognitive, instrumental, and basic ADL abilities; and the number of medications and specific concomitant medications (no/yes for each group: antihypertensive/cardiac therapy, antidiabetics, nonsteroidal anti-inflammatory drugs [NSAIDs]/acetylsalicylic acid, lipid-lowering agents, antidepressants, antipsychotics, and anxiolytics/sedatives/hypnotics) used at baseline.

In the nursing home placement models, the independent variables were age at baseline, sex, years of education, APOE genotype, MMSE, IADL, and PSMS scores at baseline and the corresponding rates of decline per month, and the amount of home-help services (hours/week) used at the last assessment prior to nursing home entry.

\section{Results \\ Baseline characteristics according to living status}

Among the 1,021 outpatients included in the SATS, 355 (35\%) were living alone at the start of ChEI therapy (shortly after the time of AD diagnosis). The sociodemographic and clinical characteristics of the participants according to living status (solitary living or living with a family member) are shown in Table 1. The individuals who lived alone were predominantly female and used more antidepressant and antipsychotic medications, but less lipid-lowering agents. They were also significantly older at the onset of $\mathrm{AD}$ and at the start of ChEI treatment

Table I Demographic and clinical characteristics and endpoints according to living status $(n=I, 02 I)$

\begin{tabular}{|c|c|c|c|}
\hline Variable & $\begin{array}{l}\text { Solitary living } \\
(n=355 ; 35 \%) \\
n / \%\end{array}$ & $\begin{array}{l}\text { Living with a family } \\
\text { member ( } n=666 ; 65 \%) \\
n / \%\end{array}$ & $P$-value \\
\hline Female sex & $30 \mathrm{I} / 85 \%$ & $353 / 53 \%$ & $<0.001$ \\
\hline Carrier of APOE $\varepsilon 4$ allele $(n=999)$ & $237 / 68 \%$ & $442 / 68 \%$ & 0.831 \\
\hline Users of home-help services at baseline & $133 / 37 \%$ & $31 / 5 \%$ & $<0.001$ \\
\hline Nursing home placement during the study & $122 / 34 \%$ & $110 / 17 \%$ & $<0.001$ \\
\hline Deceased during the 3-year study & $54 / 15 \%$ & $81 / 12 \%$ & 0.175 \\
\hline Completion rate after 3 years & $127 / 36 \%$ & $258 / 39 \%$ & 0.378 \\
\hline Antihypertensives/cardiac therapy at baseline & $|44 / 4| \%$ & $270 / 41 \%$ & 1.000 \\
\hline Antidiabetics at baseline & $14 / 4 \%$ & $36 / 5 \%$ & 0.362 \\
\hline NSAIDs/acetylsalicylic acid at baseline & $107 / 30 \%$ & $198 / 30 \%$ & 0.886 \\
\hline Lipid-lowering agents at baseline & $29 / 8 \%$ & $89 / 13 \%$ & 0.014 \\
\hline Antidepressants at baseline & $113 / 32 \%$ & $144 / 22 \%$ & $<0.001$ \\
\hline Antipsychotics at baseline & $28 / 8 \%$ & $19 / 3 \%$ & $<0.001$ \\
\hline \multirow[t]{2}{*}{ Anxiolytics/sedatives/hypnotics at baseline } & $62 / 17 \%$ & $86 / 13 \%$ & 0.051 \\
\hline & Mean \pm SD (range) & Mean \pm SD (range) & \\
\hline Estimated age at onset, years & $74.0 \pm 7.0(48-87)$ & $71.2 \pm 7.3(45-88)$ & $<0.001$ \\
\hline Age at first assessment, years & $77.1 \pm 6.4(52-88)$ & $74.2 \pm 7.1(47-88)$ & $<0.001$ \\
\hline Education, years & $9.3 \pm 2.4(7-17)$ & $9.5 \pm 2.6(7-17)$ & 0.105 \\
\hline MMSE score at baseline & $21.4 \pm 3.7(10-26)$ & $21.4 \pm 3.7(10-26)$ & 0.891 \\
\hline IADL score at baseline & $15.7 \pm 5.4(8-28)$ & $16.1 \pm 5.5(8-3 \mid)$ & 0.345 \\
\hline PSMS score at baseline & $7.8 \pm 2.6(6-21)$ & $7.3 \pm 2.1(6-20)$ & 0.002 \\
\hline Number of medications used at baseline & $3.2 \pm 2.7(0-17)$ & $2.8 \pm 2.2(0-12)$ & 0.006 \\
\hline Home-help services at baseline, hours/week $(n=164)$ & $5.7 \pm 4.4(0.5-21.0)$ & $4.8 \pm 6.2(0.5-25.0)$ & $0.47 \mathrm{I}$ \\
\hline Length in the SATS, months & $22.2 \pm 13.5(I-36)$ & $23.7 \pm 12.7(I-36)$ & 0.074 \\
\hline $\begin{array}{l}\text { Time to nursing home placement from } \\
\text { baseline, months }(n=232)\end{array}$ & $17.3 \pm 10.7(0-36)$ & $22.2 \pm 8.4(2-36)$ & $<0.001$ \\
\hline \multicolumn{4}{|l|}{ Mean dose of ChEl during the follow-up period, $\mathrm{mg} /$ day } \\
\hline Donepezil $(n=5 \mid 8)$ & $6.8 \pm 1.8(2.8-9.4)$ & $7.0 \pm 1.7(2.8-9.4)$ & 0.210 \\
\hline Rivastigmine $(n=2 \mid 2)$ & $6.2 \pm 2.2(2.5-10.5)$ & $6.1 \pm 2.1(2.3-10.5)$ & 0.708 \\
\hline Galantamine $(n=291)$ & $14.7 \pm 3.5(8.0-22.0)$ & $15.4 \pm 3.8(8.0-22.0)$ & 0.100 \\
\hline
\end{tabular}

Abbreviations: $n$, number; APOE, apolipoprotein E; NSAIDs, nonsteroidal anti-inflammatory drugs; SD, standard deviation; MMSE, Mini-Mental State Examination; IADL, Instrumental Activities of Daily Living scale; PSMS, Physical Self-Maintenance Scale; SATS, Swedish Alzheimer Treatment Study; ChEl, cholinesterase inhibitor. 
(baseline). The basic ADL capacity was more impaired among the solitary-living patients, and these individuals used a greater number of medications at baseline. The APOE genotype, years of education, cognitive and IADL abilities, and specific concomitant medications (antihypertensives/cardiac therapy, antidiabetics, NSAIDs/acetylsalicylic acid, and anxiolytics/ sedatives/hypnotics) did not differ between the two groups.

The IADL capacity was already markedly impaired at baseline: $50 \%-65 \%$ of the $\mathrm{AD}$ patients were dependent on assistance to perform these activities (IADL score: $2-5$ ). The percentage of participants with impairment in the individual IADL items was similar between the groups of patients who lived alone and those who did not, with the exception of the "shopping" and "housekeeping" tasks, for which significantly fewer solitaryliving individuals depended on assistance (Figure 1A).

Regarding basic ADL, most patients were able to manage themselves independently, with the exception of physical ambulation (more than $50 \%$ of individuals needed some assistance; PSMS score: 2-5). A significantly larger percentage of participants living alone were impaired in the ADL items "toileting", "grooming", "physical ambulation", and "bathing", whereas a greater proportion of individuals living with family needed assistance with "dressing" (Figure 1B).

\section{Solitary-living patients at baseline}

At the start of ChEI treatment, 267 (75\%) of the solitary-living SATS participants were in the mild stage of AD (MMSE score: $20-26)$. Home-help services were used by 85 (32\%) of the mild and $48(55 \%)$ of the moderate (MMSE score: 10-19) AD patients $(P<0.001)$. The mean \pm standard deviation $(\mathrm{SD})$ hours of home-help services used per week was $5.7 \pm 4.4$ hours among the individuals living alone; no differences were detected according to disease stage or sex. A significant difference in mean IADL score at baseline was observed between the mild and moderate AD patients: $14.6 \pm 4.9$ points versus 19.2 \pm 5.2 points $(P<0.001)$. The corresponding PSMS scores were $7.5 \pm 2.1$ points versus $8.9 \pm 3.4$ points $(P<0.001)$. Sex, age at baseline, and number of medications used did not differ between the solitary-living patients in the two stages of AD. No significant sex-based differences were observed at the start of ChEI treatment regarding age, cognitive and functional abilities, and number of medications used.

\section{Predictors of home-help service usage at baseline}

Among the 355 participants who lived alone, 133 (37\%) used home-help services at the start of ChEI therapy compared with $31(5 \%)$ of those living with family $(P<0.001)$. Binary logistic regression models according to living status at the start of ChEI therapy suggested that several risk factors were independently associated with the presence of home-help services. The odds ratios, their 95\% confidence intervals (CIs), and the $P$-values for these factors are listed in Table 2. Among the solitary-living AD patients, the use of home-help services was significantly associated with lower IADL capacity and a higher number of medications at baseline. These two variables correctly classified $79.7 \%$ of the individuals living alone regarding the usage of home-help services. For those living with a family member, the usage of home-help services was related to female sex, older age, lower basic ADL ability, and a greater number of medications used. These four variables correctly classified $95.7 \%$ of the patients not living alone regarding the presence of home-help services at baseline.

The mean \pm SD usage of home-help services was $5.5 \pm 4.8$ hours/week, and no significant difference according to living status was observed. Among all participants, a greater amount of home-help assistance at baseline exhibited linear associations with lower IADL $(r=0.342 ; P<0.001)$ and basic ADL $(r=0.292 ; P<0.001)$. Among individuals living alone, the amount of home-help service hours used was also correlated with IADL $(r=0.409 ; P<0.001)$ and PSMS ( $r=0.347 ; P<0.001$ ) scores; however, similar significant relationships were not observed for those living with family. Age, cognitive status, or number of medications used were not linearly associated with the amount of home-help service use in any of the groups.

\section{Clinical characteristics and endpoints after 3 years according to living status}

After 3 years of ChEI treatment, 376 participants (37\%) remained in the SATS: 108 (29\%) lived alone in their own home; 213 (57\%) lived with a family member; and $55(15 \%)$ resided in nursing homes. Seventy-seven of the 108 solitary-living individuals $(71 \%)$ used a mean of $9.2 \pm 6.6$ hours of home-help services per week, with no sexbased differences. The clinical characteristics and endpoints of the $\mathrm{AD}$ patients according to living status are shown in Table 3. The remaining solitary-living participants were mainly female, were significantly older, and had a more impaired basic ADL ability (but similar cognitive and IADL status) than did those living with a family member. The mean dose of ChEI received during the study did not differ significantly according to living status. 


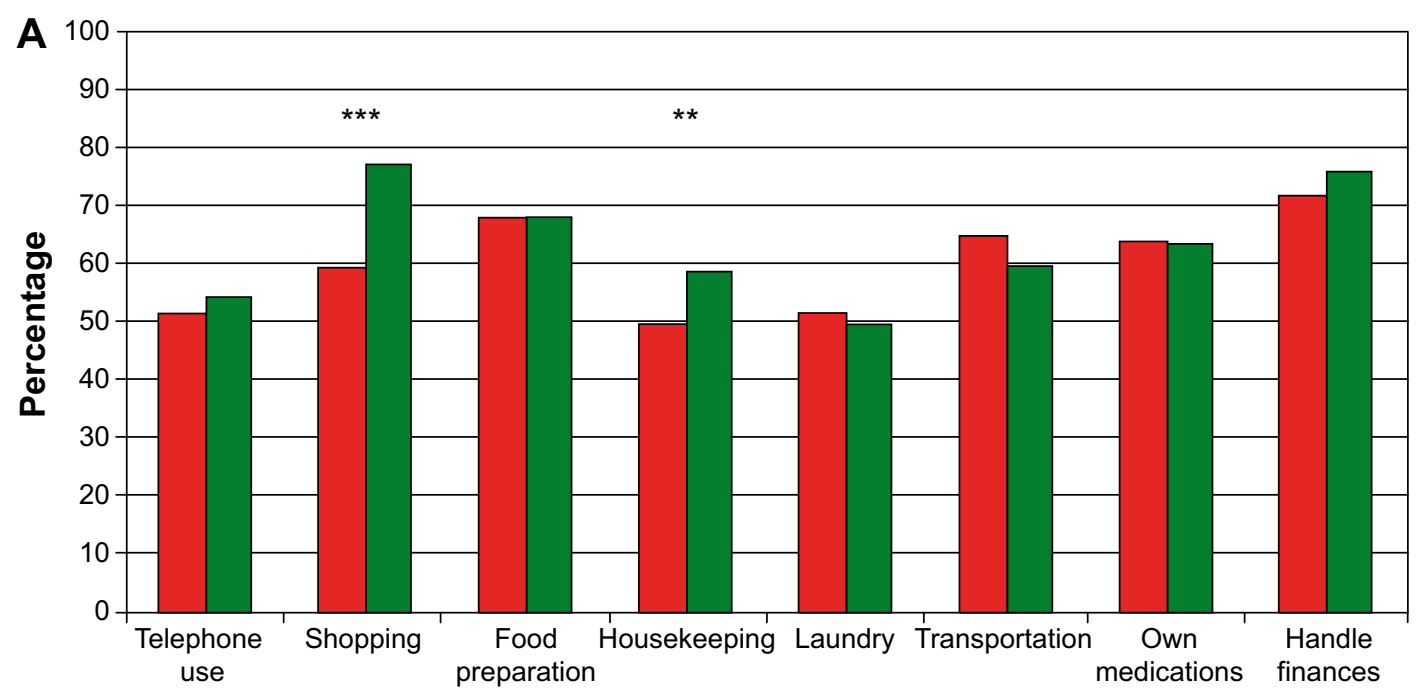

$\square$ Solitary living $\square$ Living with family

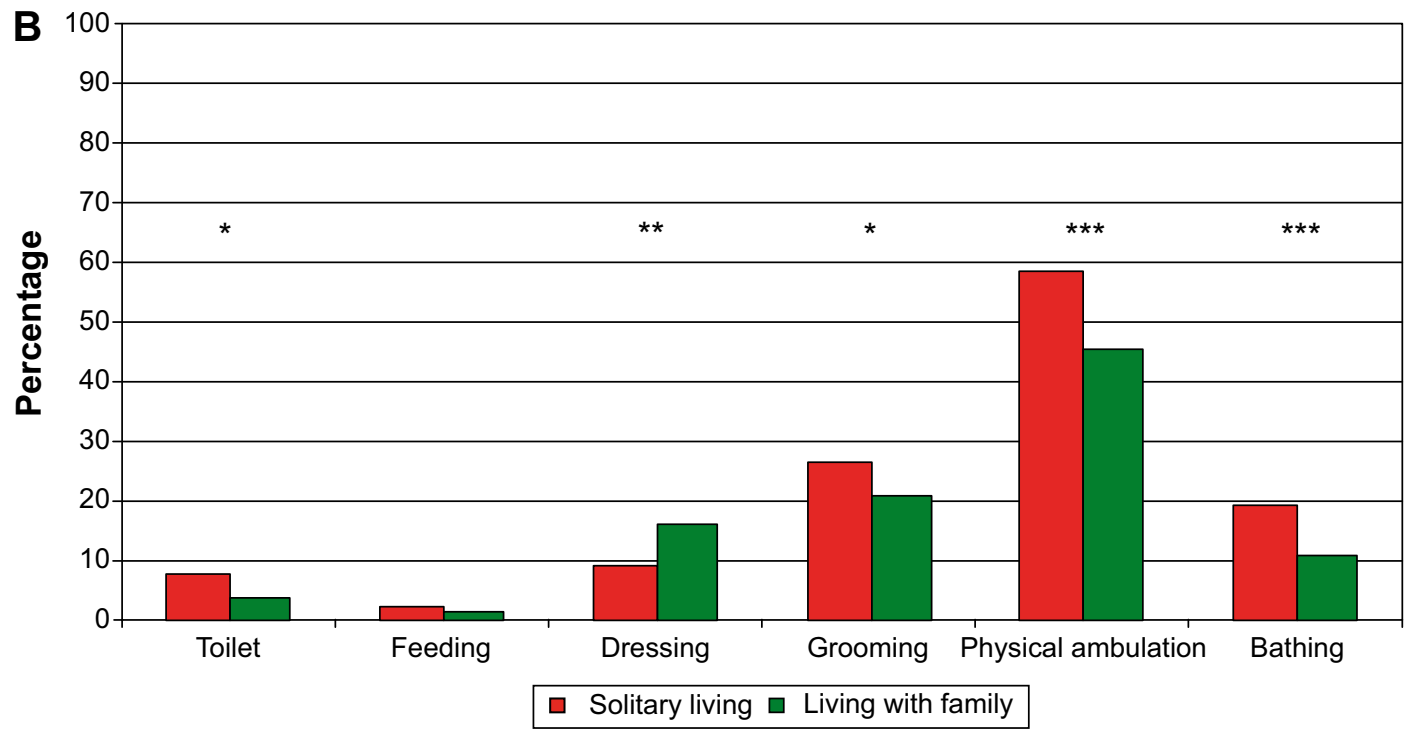

Figure I The percentage of AD patients who need help carrying out IADL and basic ADL tasks at baseline according to living status.

Notes: (A) The percentage of AD patients $(n=I, 02 I)$ who needed help to carry out IADL tasks (IADL score: $2-5)$ at the start of ChEl therapy (baseline) according to living status (***P $<0.001$; ** $0.00 \mathrm{I} \leq \mathrm{P}<0.0 \mathrm{I})$. (B) The percentage of patients $(\mathrm{n}=\mathrm{I}, 02 \mathrm{I})$ who needed help to carry out basic ADL tasks (PSMS score: $2-5)$ at baseline according to living status ( $* * * P<0.001 ; * * 0.00 \mathrm{I} \leq P<0.01 ; * P<0.05)$.

Abbreviations: AD, Alzheimer's disease; IADL, Instrumental Activities of Daily Living scale; ADL, activities of daily living; n, number; ChEl, cholinesterase inhibitor; PSMS, Physical Self-Maintenance Scale.

Table 2 Binary logistic regression analysis of the presence of home-help services at baseline

\begin{tabular}{|c|c|c|c|c|}
\hline \multirow{3}{*}{ Percent correctly classified } & \multicolumn{2}{|l|}{ Solitary living $(n=355)$} & \multicolumn{2}{|c|}{ Living with a family member $(n=666)$} \\
\hline & \multicolumn{2}{|l|}{$79.7 \%$} & \multicolumn{2}{|l|}{$95.7 \%$} \\
\hline & Odds ratio $(95 \% \mathrm{Cl})$ & $P$-value & Odds ratio $(95 \% \mathrm{Cl})$ & $P$-value \\
\hline Sex $($ male $=0 ;$ female $=I)$ & & NS & $3.01(1.23-7.36)$ & 0.016 \\
\hline Age at first assessment, years & & NS & $1.12(1.03-1.22)$ & 0.007 \\
\hline IADL score at baseline & $1.34(1.25-1.43)$ & $<0.001$ & & NS \\
\hline PSMS score at baseline & & NS & $1.46(1.28-1.68)$ & $<0.001$ \\
\hline Number of medications used at baseline & $1.20(1.08-1.33)$ & $<0.001$ & $1.18(1.02-1.37)$ & 0.030 \\
\hline
\end{tabular}

Notes: Apolipoprotein E genotype, years of education, Mini-Mental State Examination score at baseline, and specific concomitant medications (antihypertensive/cardiac therapy, antidiabetics, nonsteroidal anti-inflammatory drugs/acetylsalicylic acid, lipid-lowering agents, antidepressants, antipsychotics, and anxiolytics/sedatives/hypnotics) used at baseline were not significant factors in the models. The odds ratios are expressed per I unit increase for continuous variables and for the condition present for categorized variables.

Abbreviations: n, number; Cl, confidence interval; NS, not significant; IADL, Instrumental Activities of Daily Living scale; PSMS, Physical Self-Maintenance Scale. 
Table 3 Demographic and clinical characteristics according to living status after 3 years of ChEl treatment $(n=376)$

\begin{tabular}{|c|c|c|c|c|}
\hline \multirow[t]{2}{*}{ Variable } & \multirow{2}{*}{$\begin{array}{l}\text { Solitary living } \\
(\mathrm{n}=108 ; 29 \%)\end{array}$} & \multirow{2}{*}{$\begin{array}{l}\text { Living with a family } \\
\text { member ( } n=213 ; 57 \%) \\
n / \%\end{array}$} & \multirow{2}{*}{$\begin{array}{l}\text { Nursing home } \\
(\mathrm{n}=55 ; 15 \%)\end{array}$} & \multirow[t]{2}{*}{$P$-value ${ }^{a}$} \\
\hline & & & & \\
\hline Female sex & $87 / 81 \%$ & $113 / 53 \%$ & $44 / 80 \%$ & $<0.001(<0.001)$ \\
\hline \multirow[t]{2}{*}{ Users of home-help services } & $77 / 71 \%$ & $25 / 12 \%$ & NA & $<0.001$ \\
\hline & Mean \pm SD (range) & Mean \pm SD (range) & Mean \pm SD (range) & \\
\hline Age, years & $80.5 \pm 6.0(57-91)$ & $76.4 \pm 7.4(50-90)$ & $79.8 \pm 6.3(56-90)$ & $<0.001(<0.001)$ \\
\hline MMSE score & $20.6 \pm 5.2(6-29)$ & $19.6 \pm 6.3(0-29)$ & |3.8 $\pm 5.7(0-25)$ & $<0.00 \mathrm{I}(0.47 \mathrm{I})$ \\
\hline IADL score & $20.8 \pm 6.1(8-30)$ & $19.6 \pm 6.4(8-3 \mid)$ & $28.0 \pm 2.5(20-31)$ & $<0.001(0.308)$ \\
\hline PSMS score & $10.0 \pm 3.9(6-22)$ & $9.0 \pm 3.2(6-22)$ & $13.7 \pm 4.0(7-22)$ & $<0.001$ (0.049) \\
\hline Home-help services, hours/week ( $\mathrm{n}=\mid 02)$ & $9.2 \pm 6.6(1.0-35.0)$ & $5.1 \pm 5.2(0.5-20.0)$ & NA & 0.005 \\
\hline
\end{tabular}

Note: ${ }^{a}$ The comparison between solitary-living patients and those living with family is presented as $P$-values with the Bonferroni correction in parentheses.

Abbreviations: ChEl, cholinesterase inhibitor; n, number; NA, not applicable; SD, standard deviation; MMSE, Mini-Mental State Examination; IADL, Instrumental Activities of Daily Living scale; PSMS, Physical Self-Maintenance Scale.

The IADL capacity was strongly impaired after 3 years: $80 \%-90 \%$ of the remaining individuals living alone or with family and $100 \%$ of the nursing home residents could not carry out these tasks independently (Figure 2A). In addition, more than $45 \%$ of the participants needed assistance in performing the basic ADL item "grooming", and more than 70\% required help with "physical ambulation", regardless of living status. A significantly larger percentage of the solitary-living patients were impaired in the ADL items "toileting", "grooming", and "bathing" compared with those not living alone (Figure 2B).

Compared with those living with a family member, the percentage of participants living alone who were admitted to nursing homes during the study (34\%) was twofold, and the mean time between the start of ChEI therapy and admission was $\sim 5$ months shorter among these individuals. The percentage of deceased SATS patients did not differ between these two groups (Table 1). Regarding the solitary-living participants, nursing home placement was significantly associated with worse IADL performance or a more rapid rate of decline in IADL. These two variables correctly classified $64.6 \%$ of the individuals living alone in terms of their admission to nursing homes. For those living with a family member, nursing home placement was independently related to female sex, lower IADL capacity, faster rate of deterioration in IADL, and a greater amount of usage of home-help services at the last assessment before nursing home entry. These four variables correctly classified $82.9 \%$ of the patients not living alone regarding nursing home placement during the study. The odds ratios, their $95 \% \mathrm{CIs}$, and the $P$-values for these factors are listed in Table 4.

\section{Discussion}

In this naturalistic $\mathrm{AD}$ study, we found that a substantial number of patients (who were predominantly older females) lived alone with severe cognitive and functional impairments. The basic ADL capacity was lower and the number of concomitant medications used was higher among the solitary-living individuals compared with those living with a family member. A significantly larger percentage of the $\mathrm{AD}$ patients who lived alone used home-help services at baseline; however, no difference in the amount of home-help service usage according to living status was found. Lower IADL (solitary living) or basic ADL (living with family), but not cognitive ability, and a greater number of medications used were independent predictors of the presence of home-help services, whereas more impaired IADL at baseline and its faster rate of decline predicted nursing home placement. For individuals not living alone, female sex and older age were significantly associated with the usage of community-based services, and a greater number of home-help hours/week predicted nursing home placement. The amount of homehelp services used did not reflect the stage of $A D$ among the solitary-living individuals.

More than one-third of the participants in the present study lived alone at baseline (approximately the time of AD diagnosis). This percentage was higher than that reported earlier by studies of $\mathrm{AD},{ }^{1,9}$ and it may reflect the increasing number of solitary-living people in many countries. ${ }^{24,25} \mathrm{In}$ Sweden, most of the elderly people who do not live alone live with their spouses, and only $\sim 2 \%$ live with their adult children. ${ }^{26}$ Similar trends were observed in the other northern and western European countries. ${ }^{24}$ Furthermore, greater geographical distances between family members because of, for instance, work opportunities, and the fact that many women work full time outside the home, imply that the time available to give care to aging relatives has decreased. ${ }^{7}$ Hence, the demand and need for support from community-based services might be expected to increase. 

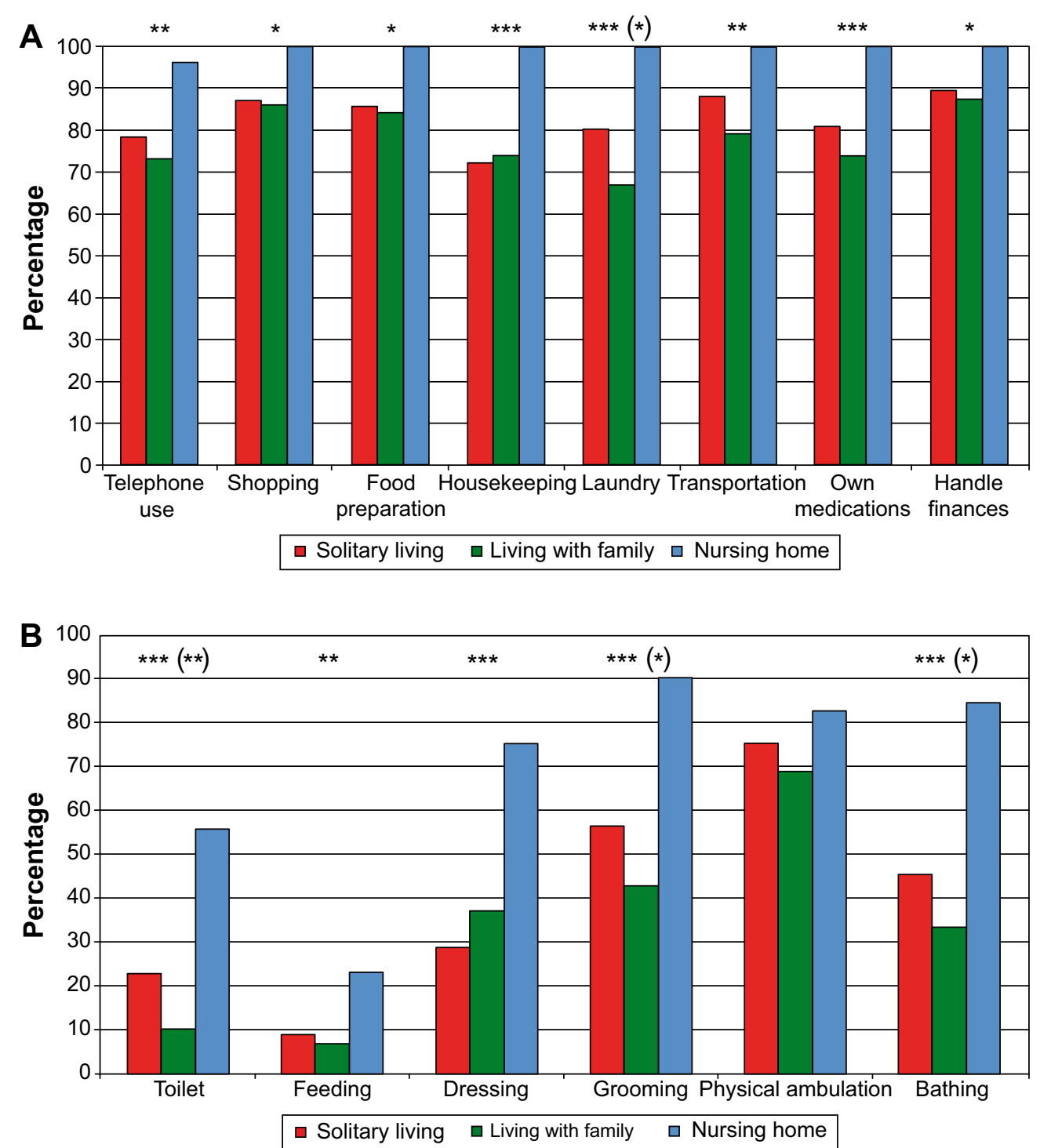

Figure 2 The percentage of AD patients who needed help to carry out IADL and basic ADL tasks after 3 years of ChEl therapy according to living status. Notes: $(A)$ The percentage of AD patients $(n=376)$ who needed help to carry out IADL tasks (IADL score: $2-5)$ after 3 years of ChEl therapy according to living status $(* * * P<0.001 ; * * 0.00 I \leq P<0.01 ; * P<0.05$; the comparison between solitary-living patients and those living with family was corrected [Bonferroni] and is presented in parentheses). (B) The percentage of patients ( $n=376)$ who needed help to carry out basic ADL tasks (PSMS score: $2-5)$ after 3 years of ChEl therapy according to living status ( $* * * P<0.00$ I; $* * 0.00$ I $\leq P<0.0$ I; $* P<0.05$; the comparison between solitary-living patients and those living with family was corrected [Bonferroni] and is presented in parentheses).

Abbreviations: AD, Alzheimer's disease; IADL, Instrumental Activities of Daily Living scale; ADL, activities of daily living; ChEl, cholinesterase inhibitor; n, number; PSMS, Physical Self-Maintenance Scale.

Table 4 Binary logistic regression analysis of nursing home placement during the study

\begin{tabular}{|c|c|c|c|c|}
\hline \multirow{3}{*}{ Percent correctly classified } & \multicolumn{2}{|c|}{ Solitary living at baseline $(n=355)$} & \multicolumn{2}{|c|}{$\begin{array}{l}\text { Living with a family member at } \\
\text { baseline }(n=666)\end{array}$} \\
\hline & \multicolumn{2}{|l|}{$64.6 \%$} & \multicolumn{2}{|l|}{$82.9 \%$} \\
\hline & Odds ratio $(95 \% \mathrm{Cl})$ & $P$-value & Odds ratio $(95 \% \mathrm{Cl})$ & $P$-value \\
\hline Sex $($ male $=0$, female $=I)$ & & NS & $1.89(1.18-3.02)$ & 0.008 \\
\hline IADL score at baseline & $1.10(1.05-1.15)$ & $<0.001$ & $1.15(1.10-1.20)$ & $<0.001$ \\
\hline IADL score, rate of change per month & $0.4 \mathrm{I}(0.17-0.97)$ & 0.043 & $0.21(0.10-0.45)$ & $<0.00 \mathrm{I}$ \\
\hline $\begin{array}{l}\text { Home-help services, hours/week at the last } \\
\text { assessment prior to nursing home entry }\end{array}$ & & NS & $1.07(1.02-1.12)$ & 0.007 \\
\hline
\end{tabular}

Notes: Apolipoprotein E genotype, age at baseline, years of education, and MMSE and PSMS scores at baseline, or their rates of change per month, were not significant factors in the models. Odds ratios are expressed per I unit increase for continuous variables and for the condition present for categorized variables.

Abbreviations: $n$, number; $\mathrm{Cl}$, confidence interval; NS, not significant; IADL, Instrumental Activities of Daily Living scale; MMSE, Mini-Mental State Examination; PSMS, Physical Self-Maintenance Scale. 
Our findings that the solitary-living AD patients had lower basic ADL capacity and used more concomitant medications than did those living with a family member are alarming. In contrast, most previous studies on dementia have reported that the functional abilities of individuals living alone were more preserved, ${ }^{10,12,14}$ or that there were no differences according to living status. ${ }^{1,13}$ This observation could be an effect of Swedish government policy over the last 2 decades, which is similar to that of other northern and western European countries - namely, that it is best for elderly people to remain in their own homes instead of being transferred to special housing accommodations. ${ }^{3}$ Therefore, those who receive care at home nowadays have a worse health status and a larger need for care. After 3 years, $46 \%$ of the remaining solitary-living individuals in this $\mathrm{AD}$ study needed help with bathing, 57\% required help with grooming, and $75 \%$ needed help with physical ambulation. Patients with dementia tend to underestimate the severity and importance of their cognitive impairment, which might lead to loss of insight and judgment. Those living alone could have problems performing tasks that are critical to daily living and are unlikely to seek the help that they may need, ${ }^{12}$ therefore, they have more unmet needs, such as those pertaining to hygiene, nutrition, and avoiding falls..$^{13}$

In the current study, no significant difference in cognitive ability was observed according to living status, which was in line with the results of some previous dementia studies. ${ }^{1,13}$ Other studies found better cognitive performance among the solitary-living participants compared with those who did not live alone. ${ }^{9,10,12}$ Cognitive status was not a predictor of the presence or the amount of home-help services used in our study. Earlier studies have reported conflicting results regarding whether there is a relationship between home health care and the care recipient's cognitive impairment. ${ }^{17}$ A recent study of $\mathrm{AD}$ performed by our group found the alarming result that a lower cognitive ability predicted fewer hours of home-help service, which suggests that these individuals were not able to request the additional formal help that they may have needed. ${ }^{18}$ However, home-help services do not directly take into account the needs associated with cognitive decline, such as supervision, controlling behavioral symptoms, and avoiding dangerous situations, but they may meet the needs of demented persons by helping them in their functional deficiencies. ${ }^{27}$ Informal help was also not sufficient to meet the needs of individuals with dementia regarding companionship and psychological distress. ${ }^{13}$ One out of four solitary-living SATS patients was in the moderate stage of AD (MMSE score: 10-19) at baseline. The percentage was slightly lower than that reported by a community-based study of cases of dementia, ${ }^{12}$ in which $18.6 \%$ of those living alone had an MMSE score $<18$ (15.2\% in our study). This level of cognitive deficiency may imply that these patients have difficulties in making informed/appropriate decisions and evaluating potential risks, which raises the question of safety for these individuals.

Lower IADL capacity was an independent predictor of the usage of home-help services for solitary-living participants with $\mathrm{AD}$ in the present study, whereas more impaired basic ADL was a corresponding predictor for those living with family. These findings indicate that family members are reluctant to provide help with basic ADL. Informal caregivers might be reluctant to provide personal care because individuals with dementia can express aggressive behaviors when receiving help with grooming, for example. ${ }^{27}$ In addition, the caregivers of recipients with more impaired ADL experience greater burden. ${ }^{14}$ Female sex and older age also independently predicted the presence of home help for individuals not living alone. Our aforementioned findings indicate that the spouse or another family member provides help with IADL for those who do not live alone; however, for female AD patients, the risk of the usage of home-help services was three times higher. Female spouses are more likely willing to perform care for a longer period when compared with male caregivers. ${ }^{28}$ In the SATS, the amount of home-help services used per week showed weak-to-moderate linear associations $(r=\sim 0.35-0.40)$ with both IADL and basic ADL for the solitary-living individuals, but not for those living with family. These observations suggest that the functional impairments of patients with AD living alone were addressed, to some extent, by community-based services.

The current study showed that IADL and its progression rate are key variables for predicting admissions to nursing homes, which was in accordance with previous AD studies. ${ }^{2,29}$ For those not living alone, the risk of nursing home placement was almost twofold for females, which again suggests that male spouses are less willing to care for their wives. For each hour of additional home-help services used, the risk of nursing home entry was $7 \%$ greater among those living with family; in contrast, this observation was not significant among the solitary-living patients. However, the percentage of individuals who were correctly classified was lower in that model, which indicated that admission to a nursing home for care recipients who live alone is more complex and depends on a larger number of factors. Because the amount of home help does not take into account the individual's cognitive impairment, this type of service might 
be less important in preventing nursing home placement for solitary-living patients. The percentage of deceased SATS participants during the 3-year study did not differ according to living status. Other dementia studies found a similar result, ${ }^{11}$ or they reported that the mortality rate of those living alone was lower compared with individuals living with a family member.,10 The explanations for the longer survival time observed among the solitary-living patients in these studies might include the higher frequency of females in this group and less or equal disease severity at baseline. In contrast, our AD patients who lived alone exhibited a worse basic ADL performance and received more medications. Furthermore, all previous studies had a shorter duration ( $\leq 2$ years).

The advantages of this 3-year, large-sample, prospective SATS study are the use of well-structured, 6-month follow-up evaluations of the various aspects of disease progression in AD (such as cognitive and functional status and their less-often analyzed rates of change over time), as well as community-based service utilization. A representative AD cohort of ChEI-treated participants with concomitant disorders and medications from Swedish memory clinics located in different geographical areas was enrolled in this study. In Sweden, the welfare state assures the right to publiclyfunded necessary care for all residents, with no obligation from relatives. The type and amount of community-based services required are evaluated according to the deficits of the care recipient in a similar way through the social service system, irrespective of municipality. Thus, services mirror the individuals' actual needs for formal care, regardless of socioeconomic status. ${ }^{26}$ The SATS program represents person-centered, high-quality, regular care and communication with a particular nurse for each participant, which entails continuity and safety for the patients and their families and $100 \%$ compliance with ChEI therapy. ${ }^{30}$

One of the limitations of this study of individuals with AD living alone was that the volume of informal care, if any, was not recorded. However, most help provided to the elderly persons with dementia was observed to come from family members living in the same household. ${ }^{10,31}$ It was noteworthy that the areas that exhibited unmet needs most frequently were those provided by relatives. ${ }^{13}$ The SATS participants were required to have a knowledgeable informant; thus, individuals with no identified caregiver were not included. Solitary-living AD patients without family might be even less likely to access needed social and medical services; therefore, they could be at greater risk of harm. ${ }^{9,12}$ The usage of community-based services may be influenced by other reasons that do not emerge from the individual's AD (eg, somatic disorders and caregiver issues), which were not investigated in the SATS. The strong predictors of service utilization identified in the multivariate statistical models in the present study are stable and consistent with earlier reports. There is no indication that these predictors would be less significant if they were mediated by other variables.

To improve and extend our knowledge of solitary living in the context of $\mathrm{AD}$, future studies are required to investigate the presence, type, and amount of informal care, as well as caregiver burden, among AD patients living alone. Furthermore, it is necessary to determine whether informal care or burden differ depending on the caregiver's relation to the patient. Additional studies are required to evaluate whether solitary-living individuals with $\mathrm{AD}$ receive the amount of formal services that they really need according to their deficits, especially cognitive impairment. Furthermore, it is essential to focus on how community-based service can best identify care recipients with dementia who are at risk of receiving an inadequate volume of service, as well as their potentially unmet needs.

\section{Conclusion}

In conclusion, this naturalistic study showed that a substantial number of AD patients, mostly older females, live alone with severe cognitive and functional deficits. Cognitive ability was not a significant predictor in the multivariate models of usage of home-help services, which suggests that formal care met the needs related to cognitive decline to a lesser extent. For patients not living alone, female sex was significantly related to community-based service utilization, and basic ADL capacity was related to home-help service usage. These findings imply that male spouses are less willing to assume a caregiving role, and that family members are reluctant to provide help regarding personal care. An increased understanding of how community-based services can better accommodate the care needs of solitary-living individuals with cognitive deficits is important.

\section{Acknowledgments}

$\mathrm{CW}$ received grants from Alzheimerfonden (Alzheimer Foundation) and Demensfonden (Dementia Foundation) in Sweden, and an ALF young researcher grant from Region Skåne, Sweden. EL received grant number 523-2010520 from the Swedish Research Council. The sponsors had no involvement in the study design, in the collection, analysis, and interpretation of data, in the writing of the report, or in the decision to submit the manuscript. 
We wish to thank all the SATS patients and their relatives for their cooperation in this study. The authors are grateful to the staff members from all of the different centers that took part in the management of the patients and provided administrative support to the study.

\section{Author contributions}

CW participated in the SATS, supervised the data collection, was responsible for the statistical design and for carrying out the statistical analyses, interpreted the results, and drafted the paper. EL participated in the study, assisted in the analysis and interpretation of the data, and revised the manuscript critically. LM was responsible for the design of the study, was the principal investigator, and revised the manuscript critically. All authors read and approved the final manuscript.

\section{Disclosure}

The authors report no conflicts of interest in this work.

\section{References}

1. Nourhashemi F, Amouyal-Barkate K, Gillette-Guyonnet S, Cantet C, Vellas B; REAL.FR Group. Living alone with Alzheimer's disease: cross-sectional and longitudinal analysis in the REAL.FR Study. J Nutr Health Aging. 2005;9(2):117-120.

2. Wattmo C, Wallin AK, Londos E, Minthon L. Risk factors for nursing home placement in Alzheimer's disease: a longitudinal study of cognition, ADL, service utilization, and cholinesterase inhibitor treatment. Gerontologist. 2011;51(1):17-27.

3. Prince M, Prina M, Guerchet M, editors. Journey of caring: an analysis of long-term care for dementia. In: World Alzheimer Report 2013. London, UK: Alzheimer's Disease International; 2013.

4. Sundstrom G. Var tredje äldre bor ensam [Every third elderly person lives alone]. In: Välfärd. Stockholm, Sweden: Statistiska centralbyrån (Statistics Sweden); 2014;1:10-11. Swedish.

5. Wattmo C, Wallin AK, Minthon L. Progression of mild Alzheimer's disease: knowledge and prediction models required for future treatment strategies. Alzheimers Res Ther. 2013;5(5):44.

6. Kim SY, Karlawish JH, Caine ED. Current state of research on decisionmaking competence of cognitively impaired elderly persons. Am J Geriatr Psychiatry. 2002;10(2):151-165.

7. Scharlach AE, Gustavson K, Dal Santo TS. Assistance received by employed caregivers and their care recipients: who helps care recipients when caregivers work full time? Gerontologist. 2007;47(6):752-762.

8. Nordberg G, von Strauss E, Kåreholt I, Johansson L, Wimo A. The amount of informal and formal care among non-demented and demented elderly persons-results from a Swedish population-based study. Int $J$ Geriatr Psychiatry. 2005;20(9):862-871.

9. Webber PA, Fox P, Burnette D. Living alone with Alzheimer's disease: effects on health and social service utilization patterns. Gerontologist. 1994;34(1):8-14.

10. Ebly EM, Hogan DB, Rockwood K. Living alone with dementia. Dement Geriatr Cogn Disord. 1999;10(6):541-548.

11. Tuokko H, MacCourt P, Heath Y. Home alone with dementia. Aging Ment Health. 1999;3(1):21-27.

12. Lehmann SW, Black BS, Shore A, Kasper J, Rabins PV. Living alone with dementia: lack of awareness adds to functional and cognitive vulnerabilities. Int Psychogeriatr. 2010;22(5):778-784.
13. Miranda-Castillo C, Woods B, Orrell M. People with dementia living alone: what are their needs and what kind of support are they receiving? Int Psychogeriatr. 2010;22(4):607-617.

14. Prescop KL, Dodge HH, Morycz RK, Schulz RM, Ganguli M. Elders with dementia living in the community with and without caregivers: an epidemiological study. Int Psychogeriatr. 1999;11(3):235-250.

15. Boström F, Jönsson L, Minthon L, Londos E. Patients with Lewy body dementia use more resources than those with Alzheimer's disease. Int J Geriatr Psychiatry. 2007;22(8):713-719.

16. Vossius C, Rongve A, Testad I, Wimo A, Aarsland D. The use and costs of formal care in newly diagnosed dementia: a three-year prospective follow-up study. Am J Geriatr Psychiatry. 2014;22(4):381-388.

17. Kadushin G. Home health care utilization: a review of the research for social work. Health Soc Work. 2004;29(3):219-244.

18. Wattmo C, Paulsson E, Minthon L, Londos E. A longitudinal study of risk factors for community-based home help services in Alzheimer's disease: the influence of cholinesterase inhibitor therapy. Clin Interv Aging. 2013;8:329-339.

19. Wallin AK, Andreasen N, Eriksson S, et al; Swedish Alzheimer Treatment Study Group. Donepezil in Alzheimer's disease: what to expect after 3 years of treatment in a routine clinical setting. Dement Geriatr Cogn Disord. 2007;23(3):150-160.

20. Folstein MF, Folstein SE, McHugh PR. "Mini-mental state". A practical method for grading the cognitive state of patients for the clinician. J Psychiatr Res. 1975;12(3):189-198.

21. American Psychiatric Association. Diagnostic and Statistical Manual of Mental Disorders, (DSM-IV). 4th ed. Washington, DC: American Psychiatric Association; 1994

22. McKhann G, Drachman D, Folstein M, Katzman R, Price D, Stadlan EM. Clinical diagnosis of Alzheimer's disease: report of the NINCDSADRDA Work Group under the auspices of Department of Health and Human Services Task Force on Alzheimer's Disease. Neurology. 1984; 34(7):939-944.

23. Lawton MP, Brody EM. Assessment of older people: self-maintaining and instrumental activities of daily living. Gerontologist. 1969;9(3): 179-186.

24. Fokkema T, Liefbroer AC. Trends in living arrangements in Europe: convergence or divergence? Demogr Res. 2008;19(36):1351-1418.

25. Sun W, Watanabe M, Tanimoto Y, et al. Factors associated with good self-rated health of non-disabled elderly living alone in Japan: a crosssectional study. BMC Public Health. 2007;7:297.

26. Lagergren $M$. The systems of care for frail elderly persons: the case of Sweden. Aging Clin Exp Res. 2002;14(4):252-257.

27. Hawranik P. The role of cognitive status in the use of inhome services: implications for nursing assessment. Can J Nurs Res. 1998;30(2):45-65.

28. Forbes DA, Jansen SL, Markle-Reid M, et al. Gender differences in use and availability of home and community-based services for people with dementia. Can J Nurs Res. 2008;40(1):39-59.

29. Hatoum HT, Thomas SK, Lin SJ, Lane R, Bullock R. Predicting time to nursing home placement based on activities of daily living scores - a modelling analysis using data on Alzheimer's disease patients receiving rivastigmine or donepezil. $J$ Med Econ. 2009;12(2):98-103.

30. Wattmo C, Jedenius E, Blennow K, Wallin AK. Dose and plasma concentration of galantamine in Alzheimer's disease - clinical application. Alzheimers Res Ther. 2013;5(1):2.

31. Wenger GC, Burholt V, Scott A. Dementia and help with household tasks: a comparison of cases and non-cases. Health Place. 1998;4(1):33-44. 


\section{Publish your work in this journal}

Clinical Interventions in Aging is an international, peer-reviewed journal focusing on evidence-based reports on the value or lack thereof of treatments intended to prevent or delay the onset of maladaptive correlates of aging in human beings. This journal is indexed on PubMed Central, MedLine,

CAS, Scopus and the Elsevier Bibliographic databases. The manuscript management system is completely online and includes a very quick and fair peer-review system, which is all easy to use. Visit http://www.dovepress. com/testimonials.php to read real quotes from published authors. 